\section{Construcción y representación de la identidad de Alto Verde y La Boca. Trabajo conjunto entre la Red Interinstitucional y Social de Alto Verde y la Universidad Nacional del Litoral}

\author{
Verónica Heinrich \\ Coordinadora del Área Territorio y \\ Políticas Públicas de la Secretaría de \\ Extensión Social y Cultural. Universidad \\ Nacional del Litoral, Argentina. \\ veronicah@unl.edu.ar \\ (iD) orcid.org/0000-0002-7805-2682

\section{Patricia Mines} \\ Docente, investigadora y extensionista \\ de la Facultad de Arquitectura, Diseño
}

RECEPCIÓN: 24/06/19

ACEPTACIÓN FINAL: 30/10/19

\section{Resumen}

Este artículo plantea una reflexión compartida entre actores universitarios y sociales sobre el complejo proceso de construcción, narración y representación de la identidad en las comunidades de Alto Verde y La Boca de la ciudad de Santa Fe. La presencia sostenida de la Universidad Nacional del Litoral —particularmente en el período 2006 a 2019 - en conjunto con instituciones públicas, organizaciones sociales y vecinos, permitió construir espacios de diálogo y de contribución a políticas públicas que pusieron en visibilidad y en valor el patrimonio social y natural de esa comunidad. En este trayecto viene cumpliendo un rol clave la Red Interinstitucional y Social de Alto Verde, como mecanismo de articulación entre instituciones académicas, organizaciones sociales, vecinos y políticas públicas. En este espacio, la universidad participa como un actor más, generando sinergia entre las capacidades académicas e institucionales y los procesos sociales locales.

A partir de la lectura reflexiva de distintos momentos de este recorrido, se propone compartir la diversidad de aportes para la abordar la problemática de la identidad de los actores involucrados, los objetivos y las metodologías utilizadas, así como los aprendizajes y desafíos de esta trama colectiva con el territorio y para la gestión de la extensión universitaria.

Palabras clave: identidad barrial, extensión universitaria, patrimonio natural y cultural.

\author{
y Urbanismo. Integrante del Programa \\ de Extensión Ambiente y Sociedad. \\ pmines@fadu.unl.edu.ar \\ (iD) orcid.org/0000-0001-5220-4185
}

\section{Bruno Reinheimer}

Docente, investigador y extensionista de la Facultad de Arquitectura Diseño y Urbanismo. breinheimer@fadu.unl.edu.ar

iD orcid.org/0000-0003-2526-3440
Cultura(s) en clave de extensión universitaria / Desafíos de gestión 다(i)(5)

\author{
Hugo Cabrera \\ Integrante de la Red Interinstitucional \\ y Social Alto Verde. \\ soyhugocabrera@gmail.com \\ (iD) orcid.org/0000-0001-7126-1142
}

\section{Construction and representation of the identity of Alto Verde and La Boca. Joint work between the Inter-Institutional and Social Network of Alto Verde and the Universidad Nacional del Litoral \\ Construção e representação da identi- dade de Alto Verde e La Boca. Trabalho conjunto entre a Rede Interinstitucional e Social Alto Verde e a Universidade Nacional do Litoral}

\section{Abstract}

This work is a shared reflection on the complex process of construction, narration and representation of identity in the Alto Verde and La Boca communities of the city of Santa Fe. From the perspective provided by the sustained presence of the National University of the Litoral in the territory -particularly in the 2006-2019 period- experiences, exchanges and products generated from the dialogue between territorial institutional actors neighbors, management teams, teachers and university students are reported, given the need to make visible and value community resources and natural In this journey, the Alto Verde Inter-Institutional and Social Network plays a key role, as a mechanism for articulation between social organizations, neighbors and public policies. In this space, the university participates as one more actor, generating links between academic and institutional capacities and local social processes.

From the reflexive rereading of different moments of this tour, it is proposed to share the diversity of contributions for the identification of the problem, actors involved, objectives and methodologies as well as conclusions learning and new challenges of this collective plot with the territory and for the University extension management.

Keywords: district identity, academic extension, natural and cultural heritage.
Resumo

Este trabalho é uma reflexão compartilhada entre atores universitários e sociais, sobre o complexo processo de construção, narração e representação da identidade nas comunidades de Alto Verde e La Boca da cidade de Santa

Fé. Do ponto de vista proporcionado pela presença prolognada da Universidade Nacional do Litoral no território - especialmente no período 2006-2019 - são relatadas experiências, intercâmbios e produtos gerados a partir do diálogo entre atores institucionais territoriais, vizinhos, equipes de gestão, professores e estudantes universitários, dada a necessidade de tornar visível e valorizar o patrimônio social e natural dessa comunidade. Neste percurso, a Rede Interinstitucional e Social Alto Verde desempenha um papel fundamental, como mecanismo de articulação entre organizações sociais, vizinhos e políticas públicas. Nesse espaço, a universidade participa como mais um ator, gerando ligações entre as capacidades acadêmicas e institucionais e os processos sociais locais. A partir da leitura reflexiva de diferentes momentos deste percurso, propõe-se compartilhar a diversidade de contribuições para abordar a problemática da identidade dos atores envolvidos, os objetivos e metodologias utilizadas, bem como as aprendizagens e desafios deste enredo coletivo com o território e para a gestão da extensão universitária.

Palavras-chave: identidade do bairro, extensão universitária, patrimônio natural e cultural.

Para citación de este artículo: Heinrich, V.; Mines, P.; Reinheimer, B. y Cabrera. H. (2019). Construcción y representación de la identidad de Alto Verde y La Boca. Trabajo conjunto entre la Red Interinstitucional y Social de Alto Verde y la Universidad Nacional del Litoral. +E: Revista de Extensión Universitaria, 9(11), 69-91. doi: 10.14409/extension.v9i11.Jul-Dic.8727. 


\section{Introducción: entramar acciones entre la Universidad Nacional \\ del Litoral y el territorio}

La Universidad Nacional del Litoral (UNL), mediante diversas acciones de extensión universitaria en el territorio, promueve escenarios de construcción de conocimientos y democratización del capital social y cultural como aspectos claves para contribuir a la transformación del medio. Las funciones universitarias encuentran el marco político de actuación en la noción de "sitio" dispuesta en el Estatuto de la UNL. ${ }^{1}$ Allí quedan explicitados el alcance territorial y el compromiso universitario con el desarrollo sustentable a partir del abordaje de problemas sociales, culturales y productivos de la región. A través de Plan de Desarrollo Institucional (PDI 2010-2019) se vehiculizan líneas que guían a la gestión. La línea vinculada a la calidad en la enseñanza, investigación y extensión del conocimiento expresa:

"Entendemos a la extensión a la luz de los principios reformistas como una dimensión que atraviesa los procesos sociales, culturales y económicos. Desde esta perspectiva, el diseño, evaluación y desarrollo de políticas, estrategias y acciones públicas es parte de una agenda compartida con el Estado y los diversos actores sociales y productivos. Desde esta visión, la extensión es una función esencial de nuestra Universidad que promueve el diálogo permanente con el Estado —en sus diferentes jurisdicciones-, con otras instituciones educativas y científico-tecnológicas del sistema provincial y nacional, con las organizaciones de la sociedad civil y de la producción en la búsqueda de soluciones a los problemas del contexto, lo que confiere a estas acciones una alta pertinencia social. De esta manera, la integración entre la Extensión y la Enseñanza nos posiciona desde una perspectiva en la que los saberes culturales y los conocimientos académico-científicos se ponen en juego con otros saberes y conocimientos que posee la sociedad, lo que posibilita analizar y abordar los problemas a partir de una concepción y comprensión de la complejidad”. (UNL, 2010:34)

En este sentido, el territorio y la relación con la apropiación social de los conocimientos conforman uno de los aspectos que marca el compás de las decisiones en políticas de extensión. Considerando al territorio según Montañez Gómez y Delgado Mahecha (1998) como:

"una construcción social, móvil, mutable y con tiempos propios; escenario de las relaciones sociales, donde la actividad de los agentes es diferencial y por lo tanto su capacidad real y potencial de crear, recrear y apropiarse del territorio es desigual(...)Espacio de poder, de gestión y de disputa del Estado, de individuos, de grupos y organizaciones, donde se sobreponen distintas territorialidades locales, regionales, nacionales y mundiales, con intereses distintos, con percepciones, valoraciones y actitudes territoriales diferentes, que generan relaciones de complementación, de cooperación y de conflicto”. (pp. 122-123 )

Es el territorio el que nos plantea el desafío, como universitarios, "de contar con canales o antenas sensibles a las inquietudes externas, y al mismo tiempo... no solo esforzarnos por mirar hacia afuera, también... ser más visibles a los ojos de su entorno" (Cortasa, 2017:70).

1) El artículo 1 del Estatuto (Resolución $N^{\circ}$ 4/12) dice que la Universidad "tiene su asiento principal en la ciudad de Santa Fe y su desarrollo prioritario en el sitio territorial centro norte de la provincia de Santa Fe, proyectando su accionar a toda la provincia, las provincias vecinas, la nación, Latinoamérica y el mundo". 
Es así que resulta imperioso constituir equipos interdisciplinarios y promover la democratización del conocimiento, por cuanto

"superar la tendencia a la creciente desigualdad en las relaciones, requiere imaginar instancias más horizontales de encuentros entre ciudadanos y comunidades científicas: instancias que favorezcan su implicación mutua en una interacción no excluyente, abierta al intercambio de saberes, valores, intereses y experiencias en pos de objetivos comunes". (Cortasa:71)

Este artículo procura ser una narración reflexiva de los procesos de construcción participativa entre actores sociales, académicos y de gestión universitaria en un territorio concreto: el barrio costero de Alto Verde y su paraje La Boca de la ciudad de Santa Fe. El desafío ante la complejidad, riqueza y singularidad territorial y social del barrio ha despertado el interés de numerosos equipos universitarios que, con diversas intensidades, vienen realizando intervenciones.

En este espacio se pretende reflexionar sobre el trabajo sostenido por la Secretaría de Extensión Social y Cultural (SESyC) y la Red Interinstitucional Alto Verde en lo que respecta a la promoción de la identidad del barrio.

Desde el trabajo universitario se focaliza la atención sobre los distintos dispositivos de gestión durante el período de 2006 a 2019 y, en especial, la acción de los últimos nueve años de equipos de la Facultad de Arquitectura, Diseño y Urbanismo (FADU), centrados en la construcción colectiva de la identidad barrial. Por otra parte, desde la Red se pondrá en relieve la trayectoria desde su creación hasta la conformación de una de las comisiones importantes y a su vez articuladora de esta experiencia a nivel barrial. En este sentido, coincidimos con Graciela Frigerio en que la "identidad es huella, es nombre... Es herencia y creación, continuidad y ruptura. Deseo de reconocimiento. Identidad es el otro nombre de la alteridad" (2003:147). Según Eduardo Pepe (2009), el hombre siempre ha construido su identidad sobre ejes simbólicos relacionados con su territorio y su historia, la singular intersección de tiempo y espacio. Néstor García Canclini explica que "el territorio se vuelve ceremonial por el hecho de contener símbolos de identidad, objetos y recuerdos (...) algo que... alude al origen y a la esencia. Allí se conserva el modelo de la identidad, la versión auténtica." (1992:178).

Para su abordaje se realiza esta escritura colectiva que reúne informaciones y miradas para "contar el barrio" y entrama la capacidad organizativa de la comunidad que se cristaliza en la Red Interinstitucional y social Alto Verde con las áreas centrales, programas, Proyectos de Extensión de Interés Social y de Educación Experiencial de la SESyC-UNL.

\section{El barrio y su impronta social, en tiempo y espacio}

Alto Verde y La Boca se sitúan en el litoral fluvial argentino, en la ciudad de Santa Fe, en el sector oeste del valle de inundación del río Paraná, más precisamente frente al Puerto, limitando con el Riacho Santa Fe al norte y al oeste y con el Canal de Acceso al oeste y al sur. Se trata de un barrio comprendido dentro del distrito La Costa de la ciudad de Santa Fe, con una notable proximidad a su casco histórico, a pesar de la distancia que imponen las aguas del río Santa Fe entre la planta urbana y este espacio singular, marcado por la predominancia hídrica y las condiciones insulares (ver Figura 1). 


\section{Figura 1. Localización de Alto Verde y La Boca en el ámbito territorial de la ciudad de Santa Fe.}

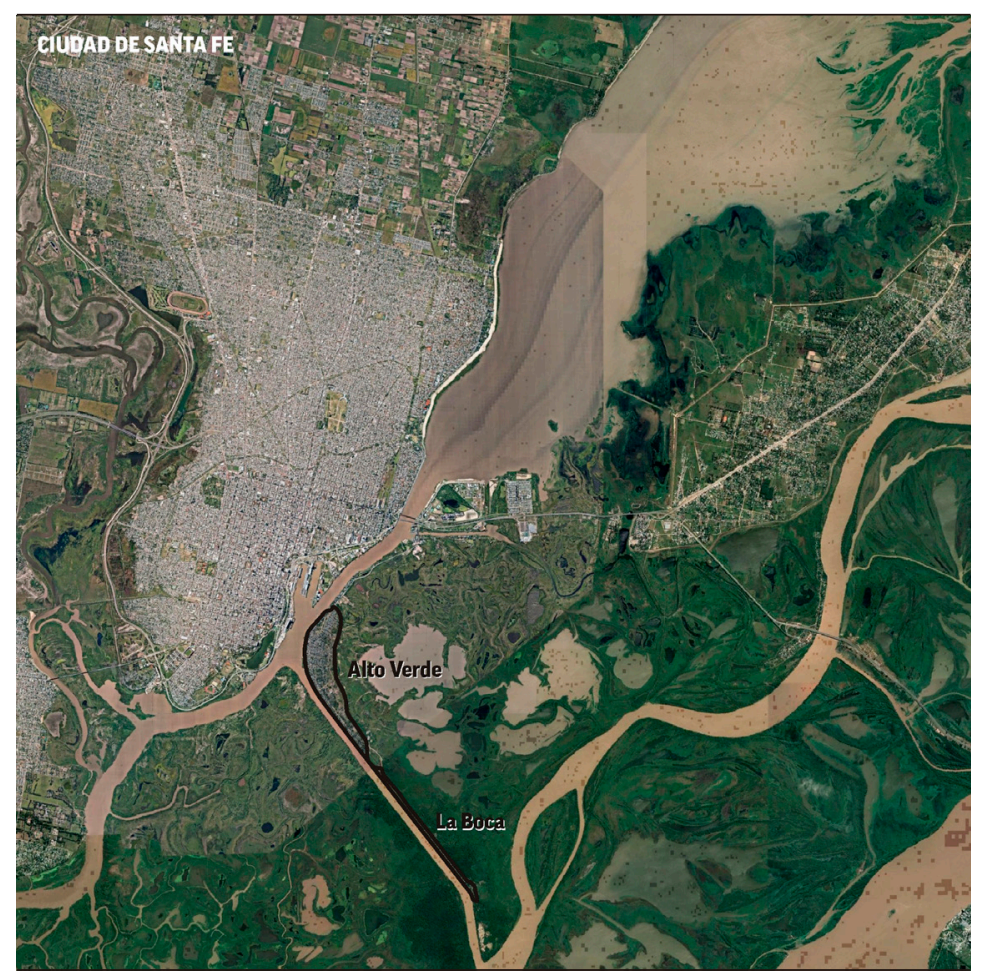

Fuente: elaboración propia sobre la base de Google Maps.

El asentamiento se originó a principios de siglo XX asociado al inicio de las primeras tareas de construcción del puerto de ultramar en 1904, en el marco del fortalecimiento del modelo agroexportador argentino. Producto de las obras de dragado para la construcción del Canal de Acceso que une las aguas de los ríos Paraná, Colastiné y Santa Fe, apareció el albardón costero bautizado "Alto Verde". Existen distintas anécdotas de cómo surgió este nombre pero todas coinciden en cuanto al significado de las dos palabras que lo componen: alto, porque no se inundaba; $y$ verde por sus envidiables condiciones naturales. Como lo describe la poetisa local Luz del Alba: "mi barrio Alto Verde, lomita de arena" (Dalla Fontana, 2019).

Allí, frente al centro histórico de la ciudad, al calor de la construcción del puerto de ultramar, se fue asentando gradualmente el personal dedicado a las tareas de obra portuaria.

Surgió así la población de Alto Verde, compuesta en su mayoría por trabajadores provenientes de Corrientes, Entre Ríos y la región, así como pescadores de la zona, a los que se sumaron tiempo después, a esta "Ionja de arena generosa", al decir del cantautor Horacio Guarany, ${ }^{2}$ familias procedentes de las provincias vecinas de Chaco y Formosa.

Hasta 1969 (año en que se construyó el Puente Palito), la única vía de contacto con el resto de la ciudad era la fluvial. En tanto, en "1989 que queda definido e integrado el dis- 
trito a través de la ordenanza municipal $N^{\circ} 7565$, en la que se fijan sus límites dentro del municipio de Santa Fe". 3

Alto Verde se desarrolla en los bordes de un río que forma parte del paisaje, de su economía y cultura, en una convivencia que implica riesgo ante "crecidas de gran porte". Los sectores más vulnerables son los cercanos a las defensas, en la proximidad de los reservorios, y por fuera del área defendida. El origen del asentamiento generó desde sus comienzos situaciones de precarización en cuanto a la tenencia de las tierras, que aún en estos días es un tema de relevancia. En algunos sectores se ha avanzado en la formalización dominial, como también en el acceso progresivo a servicios urbanos, particularmente durante los últimos años, y donde ha jugado un rol central la capacidad organizativa barrial para el abordaje de las temáticas que impactan sobre el bien común.

En la actualidad, con cerca de 15000 habitantes, la "Ionja" se ha extendido sobre una superficie de 108 hectáreas y poblado con mayor intensidad a partir de la construcción de sus defensas este y oeste contra inundaciones hacia finales del siglo XX. La estructura urbana, presenta una disposición lineal norte-sur organizada, luego del acceso por Puente Malvinas Argentinas alrededor de las calles principales Aníbal Bustamante, Demetrio Gómez (Alto Verde) y Ramón Rivero (La Boca), ubicándose a los lados pasajes que se ramifican al interior del barrio. Las familias en general son numerosas, siendo el número promedio nueve integrantes, de los cuales el $65 \%$ es menor de 14 años, con necesidades básicas insatisfechas que alcanzan al $75 \%$ de la población, por lo cual se lo considera un barrio vulnerable. Puede observarse a continuación, en el Cuadro 1, la atividad laboral según una encuesta realizada por la UNL a 107 familias de Alto Verde en el año $2012 .{ }^{4}$

Cuadro 1. Actividad laboral en Alto Verde.

\begin{tabular}{|c|c|}
\hline Actividad & $\%$ \\
\hline Changarín/Trabajo inestable & 26,2 \\
\hline Empleados & 18,6 \\
\hline Obrero sin calificación/peón & 10,3 \\
\hline Empleado/a doméstico/a & 8,4 \\
\hline Obrero especializado & 7,5 \\
\hline Trabajo no especializado & 6,5 \\
\hline Comerciante sin personal remunerado & 1,9 \\
\hline Profesional /independiente & 1,9 \\
\hline
\end{tabular}

Fuente: Observatorio Social de la UNL Panel Zonal 2 (Alto Verde). Año 2012.

3) Proyecto de Nomenclatura de las calles de Alto Verde. Realizado por la Red interinstitucional Alto Verde en el año 2012.

4) El Observatorio Social de UNL anualmente releva información de los hogares santafesinos. Dicha información constituye la ONDA de Panel. Los hogares que año a año acceden a responder una encuesta son los que pasan a formar parte del Panel. 
El paraje La Boca se encuentra al sur de la manzana 10, 5 continuidad física del barrio Alto Verde separada del resto del barrio por "el corte".6 Se trata de una faja costera de aproximadamente 80 metros de ancho por casi $3 \mathrm{~km}$ de largo limitada por tierras bajas por tres lados y por el canal de acceso del Puerto de Santa Fe por el otro. Aproximadamente 1500 habitantes se distribuyen en esta delgada faja costera. En el paraje, las dificultades de accesibilidad están sujetas a los pulsos de inundación del río Paraná. La cultura islera, los recursos naturales y el patrimonio industrial vinculado al rol portuario que dio origen al asentamiento están escasamente visibilizados y en proceso de pérdida progresiva.

La vulnerabilidad sociolaboral, problemas sociales estructurales, necesidades básicas insatisfechas e insatisfactorios niveles de inserción laboral se explican en parte por las poco diversificadas opciones de trabajo en el paraje (pesca en un $50 \%$, artesanía y servicios turísticos informales, mínima actividad portuaria, etc.) que afectan fundamentalmente a los jóvenes (Arrillaga; Grand y Busso, 2009).

Una serie de intervenciones estatales municipales y provinciales, la acción de organizaciones no gubernamentales y grupos de investigación, extensión y voluntariado universitario han identificado estos problemas y realizado sus aportes de manera más o menos coordinada.

\section{La UNL tejiendo procesos colectivos}

Entre 2004 y 2005, la SESyC se propone revisar de forma sistemática la llegada de proyectos de extensión al territorio. En este análisis (Cejas; Botta; Heinrich; Raffin y Sosa Sálico, 2005) se identifican, entre otros aspectos: percepción ciudadana de la Universidad como alejada, solicitud de mayor permanencia en barrios vulnerables, alta intensidad de proyectos en algunos lugares, escaso o nulo conocimiento entre equipos académicos mientras trabajan en un mismo sitio, fragmentación en las intervenciones, temática surgida predominantemente de necesidades universitarias y superposición de acciones. Por este motivo se crearon en 2006 los Centros Barriales UNL, ${ }^{7}$ con el fin de acompañar institucional y localmente la participación universitaria mediante coordinadores que mantuvieran vinculación hacia el interior (con equipos, proyectos, programas, acciones de extensión e investigación) y hacia el afuera (organizaciones, grupos sociales, Estado local) con la definición de una "estrategia territorial". En un primer momento se realizaron relevamientos, identificación de actores sociales y demandas, donde fue fundamental conformar un equipo interdisciplinar (psicólogo social, terapeuta ocupacional, trabajador social, arquitectos, sociólogo, técnicos en Saneamiento Ambiental, licenciados en Ciencias de Educación) en el cual cada integrante desplegó un rol

5) De los distintos sectores que componen la trama del barrio se identifican por los propios habitantes las manzanas y las calles principales; a los pasajes les dicen pasillos, a pesar de la denominación de calles por ordenanza promovida por la Red. La numeración, por el momento, no está formalmente señalada en los domicilios a pesar de que hay propuesta en la ordenanza. En este sentido, la referencia espacial de sus habitantes respecto de lotes y viviendas es primaria aún (al lado de, cerca de, más allá de..., y utilizan identificaciones como el apellido de un vecino, la torre de alta tensión, entre otros elementos).

6) Es llamado así por los vecinos el espacio del camino que une el paraje La Boca con Alto Verde, el que, cuando el río Paraná llega a los 5 metros de altura, se inunda, y queda como la única vía de comunicación habilitada un puente angosto con solo una mano de circulación.

7) Resolución del Consejo Superior de la Universidad Nacional del Litoral - Res. 200/06. A través de la misma, deja establecida la sustentablidad de la vinculación territorial a partir de la creación formal de los Centros UNL como Área correspondiente a la Secretaría de Extensión de la UNL. 
articulador, como referente de UNL, en las mesas de diálogo, consenso y gestión con actores sociales territoriales $\mathrm{y} / \mathrm{o}$ con otros entes públicos estatales. Este proceso fue dejando aprendizajes en los que se reconocen errores, potencialidades y necesidades de organización interna ante las interpelaciones del contexto.

En la actualidad continúa siendo una definición político-institucional que la extensión en sus "múltiples dimensiones: institucional, comunicacional, social, política y pedagógica" (Menéndez 2017:16) acompañe procesos territoriales, de los que la universidad misma forma parte, para potenciar y redoblar esfuerzos orientados por el compromiso social. En el organigrama de la nueva gestión de la SESyC que asumió en 2018 (período 2018-2021) el Área de Territorio y Políticas Públicas es una de las estrategias territoriales enmarcadas en el Programa de Intervención Sociocultural que, junto con otras áreas y en vinculación con programas, proyectos y prácticas de extensión, intenta pensar mecanismos para mejorar la articulación de las capacidades académicas e institucionales en su integración a los procesos sociales locales.

Uno de esos escenarios en donde se materializa esta estrategia es el barrio Alto Verde, y trabajar en conjunto con la Red Interinstitucional es uno de los mecanismos de articulación que emergen de este proceso.

\section{La Red Interinstitucional y Social de Alto Verde y la Comisión Recursero ${ }^{8}$}

En 2006, ante la diversidad de problemáticas que afectaban al barrio, y sobre todo con la intención de poder trabajar interinstitucional e intersectorialmente, nació la Red Institucional Alto Verde. Si bien con anterioridad se venían realizando encuentros entre instituciones, estos eran esporádicos y abordaban solo temas urgentes (salud, riesgo hídrico, educación, entre otros). Recién en ese año, como corolario de las reuniones con referentes de instituciones participantes de proyectos de extensión universitaria con gran densidad de acciones en este territorio, se visualizó con todos los actores la necesidad de consolidar ese espacio. Se comenzaron a realizar encuentros sistemáticos, se debatieron y buscaron ideas para concretar posibles soluciones ante las complejas situaciones que hacían a la cotidianeidad del barrio. Este espacio tiene como principal objetivo la generación de propuestas comunitarias desde el consenso, conteniendo las diferencias, diversidades y pluralismo. En ese inicio se encontraba integrado por distintas organizaciones e instituciones ${ }^{9}$ de Alto Verde (aproximadamente 20), incluyendo a La Vuelta del Paraguayo y La Boca.

Los primeros pasos para la conformación de la Red se cimentaron en la creación de un estatuto, un acuerdo escrito, que estableciera explícitamente sus fines y sus normas de funcionamiento. El órgano decisor es la asamblea mensual en la que se realizan las discusiones, se definen las propuestas, líneas y acciones. Cabe mencionar que en sus inicios participaban en ella solo los representantes de las instituciones. Además, según las inquietudes surgidas,

8) Recursero: consiste en una base de datos organizada de los recursos, servicios, programas, instituciones, entre otros elementos, de la comunidad. Son datos formales e informales de cada institución u organismo (referentes, días y horarios, modos de intervención) que pueden ser utilizados para orientar respuestas a determinadas problemáticas o demandas que surgen del trabajo en un territorio.

9) Escuelas, centros de salud, Universidad, centros de acción familiar, defensoría zonal, asociaciones civiles, como vecinales, clubes, centros culturales y deportivos en los inicios. A partir de 2008, con altibajos, la participación según demanda de la red de distintos niveles municipales, ministerios y programas del Estado provincial. 
se convoca a funcionarios municipales o provinciales para que informen o expliquen distintas proyecciones de políticas públicas. Lo actuado se escribe en un acta y es firmada por todos los asistentes para su aprobación.

A partir de 2015, los vecinos dejaron de ser los únicos que proponían temas de manera consultiva para pasar a tener un rol decisor en las asambleas, con el mismo tenor que los referentes de instituciones, y es entonces cuando cambió su denominación a Red Interinstitucional y Social Alto Verde.

En los comienzos de la Red los encuentros priorizaron una serie de problemáticas que afectaban a la zona entre las cuales se encontraban: falta de seguridad, deterioro y mantenimiento de las defensas contra las inundaciones, ausencia de un plan estratégico de desarrollo urbano y regularización dominial, basurales, solicitud de mejoras en servicios de salud, limpieza y/o erradicación de zanjas con aguas servidas, iluminación, agua potable, transporte público. Estas fueron las primeras grandes problemáticas que atravesaron, y algunas siguen vigentes con distintos grados según las zonas del barrio.

No ha sido fácil resistir los embates de las crisis económicas y políticas del país y la provincia, como tampoco aceptar las diferencias, enfoques, miradas, perspectivas; sin embargo, las crisis y las diferencias se fueron trabajando para que, lejos de fragmentar, enriquezcan y fortalezcan los procesos colectivos.

Entre los problemas principales que atravesaron este territorio son de relevancia las crecidas de los ríos en este convivir con la naturaleza; entre las últimas importantes, las de 2003 y 2007 que afectaron en gran medida a toda la ciudad de Santa Fe.

En 2008 se trabajó con Alto Verde Basura Cero mediante una campaña de concientización sobre el cuidado del ambiente, junto con las escuelas y la Universidad con proyectos de extensión. Con este accionar, además, se fomentó la preservación de la flora y la fauna de toda la zona costera, así como del río como medio de vida y ambiente natural de fundamental relevancia ecológica y social. Del mismo modo, se promovió la articulación con las autoridades y con todos los vecinos para la preservación de las defensas costeras contra inundaciones, y hoy sigue la lucha ante la presencia de microbasurales.

Otro de los orgullos de la Red es en la gestión para la construcción de un Polideportivo con un salón de usos múltiples, una pileta de natación, sanitarios y parque, en la Manzana 5. Este es producto de la primera experiencia de Presupuesto municipal participativo, que tuvo a la Red Institucional de Alto Verde como su principal aliado.

Asimismo, la necesidad de nombrar a las calles de Alto Verde venía siendo trabajada desde hacía muchos años por los vecinos e instituciones interesadas en otorgar a los habitantes del lugar la identidad barrial. En 2008 se presentó el Proyecto de Interés Social (PEIS) denominado "Alto Verde: De las representaciones a la construcción participativa de la identidad del espacio barrial". ${ }^{10}$ El equipo inició los debates respecto de la denominación de sus calles como elemento de ordenación de la ocupación informal del suelo, pero recién en 2012 se volvió a instalar este trabajo desde la Red, donde se investigó y se recuperaron las historias transmitidas oralmente de vecinos e institucionales. Surgieron así criterios de denominación con nombre propio para las calles con entrada para auto y con fechas conmemorativas para los pasillos o pasajes. Esas denominaciones tienen relación con las personas que lograron 
algo positivo a través de sus actividades y fechas de fundación de instituciones del barrio que mejoraron en lo cotidiano la calidad de vida de los habitantes. Luego se definió consensuar con la población - a partir de una campaña llamada "Un nombre para tu calle" - la votación de los nombres recopilados desde la historia, personas y fechas de reconocimiento desde la cultura popular, definir las propuestas que fueron las bases que fundamentaron la elaboración y presentación de un proyecto para determinación de la nomenclatura de las calles. Este trabajo fue un desafío de los integrantes de la Red con el Concejo Municipal para la sanción de la Ordenanza Municipal 11.988 titulada "Designación de nombres de calles, pasillos, pasajes y espacios públicos del Distrito Alto Verde", sancionada en abril de 2013.

Al mismo tiempo se inició el Plan Abre, ${ }^{11}$ con la Red presente en todo el proceso persiguiendo un sueño que se vio concretado con proyecciones del plan de obras que harían realidad el asfalto, luz y agua segura, y otras políticas públicas importantes de infraestructura que vienen desarrollándose hasta estos días.

El trabajo sobre políticas públicas es un aspecto central para la UNL y, en este sentido, acordamos con Oslak (1995) en que las:

"políticas públicas son un conjunto de acciones y omisiones que manifiestan una determinada modalidad de intervención del estado en relación con una cuestión que concita la atención, interés o movilización de otros actores en la sociedad civil. De dicha intervención puede inferirse una cierta direccionalidad, una determinada normativa, que previsiblemente afectará el futuro curso del proceso social hasta entonces desarrollado en torno a la cuestión" (pp. 112-113)

Por lo tanto, la Red es un actor clave al aportar espacios de debate, discusión, asesoramiento y propuestas en procesos, así como al enfatizar estas problemáticas en las agendas públicas.

La UNL participa en ella como un integrante más. Desde las áreas y direcciones centrales de la SESyC —en particular, actualmente desde el área Territorio y Políticas Públicas-, y con sus equipos interdisciplinares, viene acercando los dispositivos institucionales disponibles: Proyectos y Prácticas de Extensión ${ }^{12}$ así como con los Programas, ${ }^{13}$ en especial, el Programa Ambiente y Sociedad. ${ }^{14}$

11) Plan Abre es una política social estratégica que fortalece el territorio y convoca a la participación social desde una mirada integral. Promueve la coordinación entre diversas áreas que conforman el Gabinete Social de la provincia de Santa Fe, los gobiernos locales de los grandes centros urbanos (Rosario y Santa Fe) y sus áreas metropolitanas (Villa Gobernador Gálvez, Pérez, Granadero Baigorria y Santo Tomé). Este Plan impulsa la construcción colectiva de decisiones y el compromiso compartido entre la ciudadanía, el Estado provincial y los municipios.

12) Según el Reglamento del Sistema Integrado de Programas y Proyectos de Extensión, los proyectos y prácticas de extensión "se conforman como un modo más de articulación e integración de la Universidad con el medio social contribuyendo a la promoción del desarrollo local y regional y a la mejora de la calidad de vida de la población. Son unidades autónomas de acción que deberán estar relacionadas con Programa de Extensión. Cuentan con la asignación de recursos humanos, materiales y financieros para la ejecución de un conjunto de actividades interrelacionadas necesarias para el logro de objetivos específicos en un área determinada" (UNL, 2018).

13) Los programas constituyen una instancia política y de gestión que aborda una determinada problemática que es considerada significativa para la Universidad y forman parte de las preocupaciones más importantes de la agenda pública.

14) El Programa de Extensión Ambiente y Sociedad UNL busca contribuir al análisis, reflexión y resolución de los problemas ambientales que se plantean en la sociedad actual y aporta también a la construcción de una visión colectiva acerca del desarrollo sustentable. Para ver en detalle los aspectos del Programa, consultar Mihura (2013). 
La Comisión Recursero se creó, según acta del 4 de febrero de 2015, con los objetivos de identificar y reconocer todos los recursos instituciones (en forma actualizada) en ubicación territorial, utilizar la nueva nomenclatura de calles impulsada en 2012 por la Red, y colaborar en el fortalecimiento de la identidad barrial. La premisa fundamental que se sostuvo en el seno de la Red fue propiciar el reconocimiento de las capacidades comunitarias institucionales existentes, empoderar a quienes participaban, y dar cuenta sobre: las instituciones con sede $\mathrm{o}$ acciones en el barrio, el tipo de dependencia que presentaban (nacional, provincial, municipal, sociedad civil, movimiento comunitario), la ubicación, el tiempo que estaban en el barrio, el tipo de actividades que desarrollaban, y si formaban parte o presentaban su consentimiento para conformar la Red.

La Comisión se compuso con referentes del Gabinete Social, Centro de Acción Familiar y Policía Comunitaria del gobierno de la provincia de Santa Fe, vecinal, radio comunitaria de Alto Verde, y de la SESyC-UNL.

Con estas finalidades se iniciaron visitas y entrevistas a miembros de las instituciones para hacer los primeros mapeos, de modo de plasmar la información básica. A partir de este trabajo intersectorial, se pudieron reconocer más de 40 instituciones, algunas desvanecidas y $\sin$ funcionamiento y otras que tenían trayectoria de años, existían con gran esfuerzo y estaban en recambio generacional. Se realizó un borrador de cuadernillo-guía en donde se identificó en un mapa muy precario la ubicación de cada institución y se destinó una página con el detalle de la información recogida. Se imprimió y distribuyó un ejemplar para cada institución.

Desde la mirada del urbanismo y la arquitectura, la escala, superficie y densidad que presentan asentamientos como Alto Verde (atravesados por una condición histórica de enclave y aislamiento físico, débil pertenencia a la ciudad formal y relativa vivencia al margen de las reglas, condiciones y convenciones de la urbanidad tradicional), este caso representó un interesante desafío disciplinar al cual poder aportar.

El relato de tres momentos asociados al trabajo concreto de dos equipos de extensión de la FADU, en el período 2011-2019, da cuenta de modos de intervención en los que identidad barrial, extensión universitaria y políticas públicas se intentan articular.

\section{Momento 1: Propuesta de desarrollo turístico sustentable en el Paraje La Boca ${ }^{15}$}

Desde 2011, el equipo de extensión compuesto por docentes, investigadores y estudiantes -mayoritariamente de Arquitectura, pero también de Ingeniería en Recursos Hídricos, Biología y Turismo-, venía trabajando en Alto Verde en el PEIS "Guardianes del río" y ciclo de proyectos asociados. Con la consigna de contribuir a la consolidación de la identidad insular en el distrito La Costa y al aumento de la sensibilidad y responsabilidad ciudadana que requiere el habitar en el valle de inundación del río Paraná, se reconoció la necesidad de conciliar crecimiento económico, solidaridad social y cuidado de la naturaleza, desde un enfoque integrador de los valores naturales y culturales. Desde ese entonces, se integra a los

15) Proyecto de Extensión universitaria "Nuevos territorios, nuevos consensos. Propuesta de desarrollo turístico sustentable en el Paraje La Boca". FADU. Financiado por la Secretaría de Políticas Universitarias, Ministerio de Educación de la Nación. Programa de Promoción de la Universidad Argentina. $22^{\circ}$ Convocatoria de Extensión Universitaria y Vinculación comunitaria: Universidad, Estado y Territorio SPU No 3408/15) 2016-2017, en asociación con el PEIS "Nuevos territorios. Nuevos consensos. Propuesta de desarrollo de turismo sustentable en Paraje La Boca II", Código: 2015-48-PEIS-FADU-PM /RCS N 571/15) 2016-2018. 
jóvenes alumnos y exalumnos de la Escuela Omar Rupp de Alto Verde primero, y a la población local después, en el proceso de reconocimiento y construcción del patrimonio del barrio en relación con las islas y el Puerto así como la generación de oportunidades de empleo en el marco de una oferta turística local. ${ }^{16}$ De esa fecha data el convenio de mutua colaboración entre la UNL y la Municipalidad de Santa Fe para la preservación del entorno natural, histórico, cultural, y la valorización turística del barrio costero de Alto Verde. Esta experiencia recibió en 2012 el Primer Premio de Extensión Arquisur. ${ }^{17}$ En 2015 se sumó al proyecto un convenio de concesión de la embarcación la Ribereña para realizar paseos náuticos a cargo de los jóvenes capacitados. Esta actividad fue declarada de interés por el Concejo Municipal.

La convocatoria a presentar proyectos de la SESyC, en 2015, promovió líneas específicas para dar respuesta a la demanda de la Comisión de Recursero. A la vez, un nuevo proyecto con financiación de la Secretaría de Políticas Universitarias de la Nación puso al equipo ante el desafío de ajustar objetivos específicos y resultados previamente planificados a necesidades y tiempos concretos de esta comunidad.

La propuesta sobre el desarrollo de un turismo sustentable como estrategia para abordar transdisciplinariamente un proyecto integral para el paraje La Boca suponía la necesaria construcción de consenso y una visión compartida sobre el territorio, su patrimonio y sus posibilidades. El proceso de degradación de los ricos recursos naturales, la memoria frágil sobre la histórica modelación de la forma territorial y la noción generalizada de espacio isotrópico y homogéneo que desde la ciudad se tiene sobre los territorios rururbanos de la extensa periferia urbana eran parte de la problemática identificada. La metodología implicaba la construcción de conocimientos a partir del diálogo de saberes sustentado en reiterados recorridos por tierra y agua, conversatorios, entrevistas a informantes clave y mapeos colectivos.

Para la disciplina urbano-arquitectónica, habituada al ejercicio proyectual del espacio, la propuesta iría en la dirección de proporcionar sentido mediante colaboración activa y proactiva en la creación y la representación social de significados (Manzini, 2015).

El mapa, como imagen, es una manera de fijar un territorio. Como se dijo más arriba, si el territorio es construcción social, escenario de las relaciones sociales, un mapa

"tanto en la selectividad de sus contenidos, como en sus signos y estilos de representación, (...) son una manera de concebir, articular y estructurar el mundo humano, que se inclina hacia, es promovido por, y ejerce una influencia sobre grupos particulares de relaciones sociales". (Harley, 2005:80)

Conscientes de estas relaciones y prácticas de poder, la estrategia gráfica de estos mapas se orientó hacia la representación de los nombres, del territorio valorado y patrimonializado de la identidad.

Lo que se representa se refiere entonces tanto al capital institucional que venía identificando la Comisión Recursero como al patrimonio natural y cultural. Patrimonio entendido

16) Para conocer en profundidad esta experiencia, ver Mines y Giavedonni (2016).

17) Arquisur es la Asociación de Escuelas y Facultades de Arquitectura Públicas de América del Sur fundada en 1992 , conformada por instituciones de Argentina, Bolivia, Brasil, Chile, Paraguay y Uruguay. Constituye un espacio académico basado en la cooperación científica, tecnológica, educativa y cultural de todos sus miembros.

Entre sus actividades se destacan la realización anual de encuentros y congresos y la premiación de proyectos, prácticas e investigaciones. 
como conjunto de bienes no congelados ni fijos sino, como aclara García Canclini (1992), parte de prácticas sociales en las cuales se les atribuyen valores a ser transmitidos y resignificados, de una época a otra, de una generación a las siguientes. "Así un objeto se transforma en patrimonio o deja de serlo, mediante un proceso individual o colectivo que afirma su nueva condición" (Dibam, 2005:8). Se incorporan los iconos representativos del territorio insular y los sitios de valor patrimonial natural asociados a la hidrografía, la fauna y la flora de la ecorregión del delta e islas del Paraná, y cultural ligados a la historia del barrio en relación con el Puerto.

Entre los resultados más destacados de esta etapa se distinguen, por un lado: la propuesta de construcción de los mapas distribuidos estratégicamente en todo el barrio y sus parajes como medio más adecuado para visibilizar información que alcance mayor difusión entre vecinos y visitantes; un sistema gráfico simbólico que representa las distintas institucionalidades (educativas, deportivas, religiosas, de seguridad, etc.) a partir de iconos que fueron pensados desde lo colectivo alejados de estereotipos y atentos a las políticas públicas; y la inclusión de aspectos identitarios territoriales basados en el patrimonio natural y cultural como piezas clave en el proceso de empoderamiento de la población barrial. Por otro, la ejercitación de mecanismos e instancias de generación de consenso y democracia barrial, un proceso sostenido de construcción de confianza de los equipos universitarios en el territorio y la adquisición de capacidades para reorientar prácticas y desarrollos académicos hacia procesos de apropiación social del conocimiento.

\section{Momento 2. Sistema de referencias espaciales: estrategias de mapeo colectivo e interpretación del paisaje ${ }^{18}$}

Las Prácticas de Extensión de Educación Experiencial (PEEE) constituyen otro dispositivo de la UNL que permite incorporar la extensión universitaria al curriculum. ${ }^{19}$ Tal como lo expresa Alicia Camilloni (2009):

"la Educación Experiencial, es una estrategia de enseñanza con enfoque holístico, que está destinada a relacionar el aprendizaje con la vida real. Con ese fin, propone al alumno realizar actividades en las que, a partir de esa conexión con la práctica, desarrollarán experiencias que plantean poner en diálogo en situación auténtica las habilidades y los conocimientos teóricos que poseen, evaluarán el estado de situación de los procesos sociales, enriquecerán esos conocimientos y habilidades, realizarán aportes a posibles soluciones e identificarán nuevos problemas". (p. 15)

Así surge un proyecto derivado, por una parte, de una tesis de grado de $F A D U^{20}$ a partir de la inquietud de sus autoras por seguir vinculadas a la reflexión y acción sobre este terri-

18) PEEE de FADU-UNL, "La identidad Urbana de Alto Verde, ciudad de Santa Fe. Sistema de referencias espaciales en barrio espontáneo a partir de estrategias de mapeo colectivo e interpretación del paisaje". Convocatoria 2017, aprobado según Rs. CS. de la UNL N 2590/17. Equipo docente: Ms. Arq. Bruno Reinheimer (responsable de la práctica), Arq. Javier Poretti. Equipo de tutores: María Florencia Albizzati, María Laura Notta, Andrea Dalmolín, Rocío Vastos. Equipo de estudiantes: Luciana Cicaré, Facundo Citera, Santiago Cortese, Fernanda Delbón Torossi, Andrés Goldemberg, Joaquín Martínez, Valentín Monje, Julián Muller, Agustín Musuruana, Camila Scetti, Belén Schlatter, Emilia Tkaczyk.

19) Para más detalles de este dispositivo, consultar Boffelli y Sordo (2016); Rafaghelli (2016); Menéndez y Taravella (2016).

20) Ver Albizzati; Dalmolín; Notta; Vastos (2016). 
torio desde el ámbito académico, ya en condición de profesionales. Y por otra parte, ante un requerimiento del Área de Territorio y Políticas Públicas de la SESyC que venía participando como integrante de la Red.

La experiencia fue realizada durante dos cuatrimestres en el marco de las asignaturas Urbanismo II y Taller de Proyecto Urbanístico —Cátedra Valiente, de la FADU— y recientemente reconocida con el $3^{\circ}$ Premio de Extensión Arquisur 2018. El trabajo significó retomar parte del camino recorrido por otros equipos en este territorio a los fines de repensar soportes de referenciación física y espacial que permitan apreciar en su conjunto los recursos físicos culturales y naturales con que cuenta el barrio, para su máximo provecho en particular y el de la ciudadanía santafesina en general. Se tomó como desafío la visibilización de este territorio poroso, mutable, dinámico, para hacer una lectura de las condiciones territoriales que involucre las miradas de los actores locales.

El espíritu integrador de la propuesta se resume en la articulación de las capacidades instrumentales y los conocimientos disciplinares de los alumnos de urbanismo, coordinados por el equipo de docentes y tutores, con el trabajo iniciado por la Red Institucional y Social Alto Verde junto a vecinos. La Universidad aporta el conocimiento disciplinar para construir conjuntamente un sistema de referencias espaciales que consolide, visibilice y amplíe la iniciativa de nomenclatura de calles, pasillos, pasajes y espacios públicos surgida de la Ordenanza Municipal 11.988/13, de modo de reforzar el sentido de pertenencia barrial y contribuir a su reconocimiento para uso y orientación corriente por parte de los vecinos y visitantes. El equipo extensionista se hace parte de la Comisión Recursero de la Red para responder a la problemática emergente con criterios académicos adaptados a las necesidades del medio.

La propuesta académica de ejercitación sobre el caso concreto plantea relevar, clasificar y representar con rigor metodológico y sobre distintos soportes y escalas gráficas la complejidad y singularidad del barrio (instituciones, espacios públicos, viviendas, calles y pasajes, reservorios, grandes infraestructuras, etc.) en relación con la ciudad y su entorno natural dominante, con estrategias gráficas que permitan la rápida interpretación y lectura del ciudadano común.

El proceso de trabajo se caracterizó por instancias de producción, discusión y puesta en común de lo producido a partir de relevamientos por tierra y por agua, experiencias de mapeo colectivo, digitalización y edición de la información obtenida, difusión en el barrio y participación en reuniones periódicas de validación de la Red, hasta alcanzar una base gráfica digital de amplio consenso barrial adaptable a distintos soportes y escalas (pequeño y gran tamaño).

Los resultados concretos consistieron, en una primera instancia, en un folleto tríptico impreso en cantidad para llegar a todas las instituciones, organizaciones sociales y vecinos comprometidos en el marco de la Red. En una segunda instancia, la construcción de tres tótems informativos diseñados desde el proyecto, a la manera de dispositivos estructurales ejecutados con tecnología accesible (constructibilidad local) y recurriendo a las capacidades técnicas y humanas del barrio (mano de obra local), para instalar en el espacio público los paneles que resumen los recursos comunitarios (identidad local). Un fruto para y desde el barrio. Los mismos fueron implantados en el espacio público de Plaza de la Paz, Vecinal ProMejoras Alto Verde y Plaza Evita, lugares estratégicos en los tramos norte, centro y sur de la calle principal Demetrio Gómez, acompañando de esta manera el proceso de transformación que vive el barrio a partir de la consolidación progresiva de este eje estructurante norte-sur 
tan importante. Las tareas de construcción estuvieron finalmente a cargo de la Asociación local Arroyito Seco, integrante de la Red, con la coordinación del equipo extensionista. El presupuesto para su ejecución (materiales y mano de obra) excedía naturalmente los fondos propios de la práctica académica, con lo cual fueron fundamentales las gestiones del equipo con el Estado provincial en el marco de las acciones de transformación del barrio impulsadas desde el Plan Abre. Con los tótems ya construidos, el equipo extensionista tomó distancia poniéndolos a disposición de la Red para su apropiación barrial a partir de intervenciones artísticas que exalten valores propios de la cultura local. Si bien desde la práctica se facilitó a modo de insumo una guía de criterios disciplinares, sugerencias y recomendaciones para abordar la morfología y escala de estas estructuras monolíticas, las intervenciones artísticas fueron íntegramente conducidas y desplegadas desde la Red y con la colaboración de la Municipalidad de Santa Fe en el diseño de la propuesta estética y la coordinación de su concreción. Con esta acción de distanciamiento transitorio, el equipo extensionista promovió la plena participación colectiva en las intervenciones en pos de la apropiación barrial de los tótems, resignando aspiraciones estéticas propias, priorizando procesos colectivos por sobre la impronta del equipo en los resultados materiales finales.

La Red definió realizar reuniones con las instituciones y vecinos próximos a la ubicación de cada tótem. Si bien el primer mobiliario estuvo en pie listo a fines de diciembre 2018 y el último en abril de 2019, fue recién en julio de este año que se terminó de identificar cuál iba a ser el contenido a plasmar en las intervenciones artísticas. En los primeros encuentros se desplegaron distintas ideas (frases, letras y cantantes, personalidades, objetos, fauna y flora locales). Una vez consensuadas las ideas, el equipo de Intervenciones Urbanas de la Municipalidad de la ciudad de Santa Fe presentó distintos diseños a la Red para la selección final. Los mismos sintetizan los recursos comunitarios, culturales y naturales que acompañan las representaciones gráficas (mapas). Fue así que surgieron para cada uno de los tótems distintos motivos que plantean un recorrido de la historia e identidad del barrio.

Cada tótem contiene, sobre un fondo en colores marrones y verdes, un mapeo del barrio con delimitación de la trama irregular característica del sitio. En el primer plano del primer tótem, en Plaza de la Paz, aparece una canoa navegando por el río junto a irupés, planta autóctona del lugar, y una guitarra criolla que caracteriza el folclore local. En el segundo tótem, ubicado frente a la sede de la Vecinal Pro-mejoras Alto Verde, se impone un gran cardenal en una rama de árbol de ceibo. En el tercer tótem, el de la Evita, aparecen el río, la flor de irupé y las especies de peces locales: sábalo, amarillo y surubí. Participaron de estas intervenciones artísticas alumnos y docentes de las Escuelas $N^{\circ} 95 y \mathrm{~N}^{\circ} 533$ y niños de la ONG CILSA que forman parte de la Red Alto Verde.

Compartimos las palabras de una de las docentes que participó en la etapa final de la intervención artística:

"En relación con esta actividad de extensión universitaria y red de instituciones, desde la escuela 95 siempre hubo un gran apoyo desde la dirección. Los chicos, muy contentos de plasmar una imagen en la plaza más cercana a su escuela, a su casa, a su manzana, en su barrio y poder plasmar una huella relacionada con la identidad de Alto Verde. Fue una actividad muy integradora, nos sentimos muy conformes y cómodos con nuestra participación en todas las etapas del proceso. Tenemos muchas expectativas de cómo quede finalmente el tótem con su gráfica informativa. Estamos agradecidos y satisfechos 
con el trabajo general tantos con las otras instituciones de la red, como con UNL, con el gobierno de la ciudad, de la provincia y de todos los sectores involucrados. Gracias por el respeto en el transcurso de este trayecto". (Entrevista a docente Prof. de Artes Visuales de la Escuela $N^{\circ}$ 95, 4 junio de 2019)

Para el equipo del proyecto de extensión las intervenciones resultaron bastante alejadas de lo imaginado y previsto con criterios disciplinares. Esto habla de las distintas miradas que acarrea una concreción colectiva a partir de acciones conjuntas entre instituciones y organismos tan heterogéneos, con dispar grado de compromiso. Así se desprende la importancia de una clara definición y cumplimiento de roles precisos por cada parte involucrada y también la necesidad de asumir que los resultados materiales producto de una construcción colectiva son más difusos, diluidos y desdibujados que los esperados desde el rigor de la disciplina. En el proceso final, el último paso, nuevamente a cargo de Arroyito Seco, implica el montaje de los paneles informativos sobre los tres tótems para su inauguración, prevista en el marco de los festejos del $109^{\circ}$ aniversario del barrio.

Esta experiencia de materialización, sin dudas compleja a la hora de ser llevada a la práctica, sentó algunos precedentes de acción y gestión en términos de la necesaria articulación ordenada desde la Universidad con otras instituciones del medio, en especial aquellas gubernamentales con capacidad de decisión y acción, lo cual dejó disponible un antecedente de pasos a seguir, una hoja de ruta, clarificando de esta manera el camino crítico para iniciativas similares.

En el plano estrictamente académico, los resultados se reflejaron positivamente en la motivación de los grupos de estudiantes universitarios, que lograron poner en práctica los contenidos curriculares sobre un caso concreto, haciendo uso de las herramientas propias de la disciplina urbanística a los fines de relevar, clasificar y representar con rigor metodológico el barrio respecto de la ciudad y su entorno. El estudiante afrontó el desafío de analizar la complejidad urbana de Alto Verde entre defensas en su condición de singularidad como barrio de origen informal y crecimiento espontáneo, identificando los componentes y dimensiones conceptuales de la disciplina urbanística que permiten una clara comprensión del espacio (trama vial, tejido edilicio, espacio público, movilidad y transporte público, equipamientos comunitarios, paisaje, etcétera).

En todo el recorrido transitado, las herramientas e instrumentos propios de las disciplinas de Arquitectura, Diseño y Urbanismo, si bien no han sido los únicos, se han adaptado a los desafíos de interpretar y plasmar la identidad de una comunidad, que es dinámica y está en permanente construcción. En términos estrictamente metodológicos, se buscó la integración de la perspectiva tecno-científica Top-down y la participativa Bottom-up dentro de un mismo marco (Fraser et al., 2005), proponiendo dicha conjunción entre recursos conceptuales, teóricos y prácticos de índole académica (disciplinares, científicos) y saber empírico local. La academia actúa y articula en el territorio con una mirada emergente, a través de la participación y construcción de conocimientos junto a las principales instituciones, la comunidad, las organizaciones sociales y referentes barriales. 


\section{Momento 3: La Boca: propuesta de turismo sustentable en la Micro Región Insular ${ }^{21}$}

En el paraje La Boca, su ubicación estratégica entre el canal y el río Colastiné, las riquezas naturales y su patrimonio cultural conformado por la vida en las islas y las actividades portuarias que en ella han tenido lugar, han orientado al equipo de extensión en sus ocho años de trabajo. Ello con la finalidad de contribuir al desarrollo sustentable de La Boca, Alto Verde, a partir de conciliar solidaridad social, crecimiento económico y cuidado de los recursos naturales y culturales como vía para el mejoramiento de la calidad de vida de la población. Muchos de estos recursos están escasamente visibilizados, en proceso de degradación, y pueden perderse ante el avance de una urbanización descontrolada e indiferente. Por un lado, la memoria popular, en la medida en que depende de las personas, es una "memoria corta". Su efectivo rescate incluye la apropiación colectiva y democrática, es decir, crear las condiciones materiales y simbólicas para que todos puedan compartirla y encontrarla significativa (García Canclini, 1993). En este sentido, Bertuzzi (2009) habla de un paulatino proceso de "borrado de la memoria" de la cultura islera en todo el territorio costero santafesino.

Por eso el proyecto se plantea como objetivo específico la visibilización del patrimonio natural y cultural del paraje, en la búsqueda de una identidad que sirva para pensar el presente y proyectar un futuro a partir de la creación de una oferta turística de calidad, de base comunitaria, articulada a escala territorial.

En una asociación sinérgica con el Programa Ambiente y Sociedad (PAS), se propone la integración de La Boca a una red de centralidades distribuidas en todo el área del valle de inundación del río Paraná, en lo que se denomina - a partir de una investigación ligada al PAS- ${ }^{22}$ Micro Región Insular Santa Fe, San José del Rincón y Arroyo Leyes.

Esta iniciativa de colaboración entre la Universidad y los gobiernos locales de Santa $\mathrm{Fe}$ (distrito La Costa), San José del Rincón y la comuna de Arroyo Leyes, con el acompañamiento de la Secretaría de Turismo de la Provincia de Santa $\mathrm{Fe}$ ) se funda en la identificación de características territoriales y culturales, sus conflictos y potencialidades ${ }^{23}$ que hacen del área un "laboratorio a cielo abierto" en donde la gestión interjurisdiccional asociativa e integrada se yergue como la clave que

"podrá transformar a estos sistemas complejos en sujetos del desarrollo, con capacidades suficientes para gestionar la implementación de medidas en los sistemas superiores; construir planes y proyectos que generen procesos de desarrollo sustentable (económicamente viables, con equidad social y cuidado de los recursos)". (Mihura, 2011:69)

21) PEIS Paraje La Boca: Propuesta de turismo sustentable en la Micro Región Insular. FADU/UNL. Equipo de Extensión: Mines, Patricia; Giavedoni, Ricardo; Albizzati, Florencia; Goldsack, María Carolina; Robles, Ricardo; Molina, María Sol; Tibaldo, Alejandro; Barbieri, Gabriel (FADU); Villalba, Andrea; Rodríguez, Alba Rut (Facultad de Humanidades y Ciencias - FHUC); Mihura, Enrique; Agostinelli, Carla; Zilli, Daina (Facultad de Ingeniería y Ciencias Hídricas $-\mathrm{FICH}$ ).

22) Curso de Acción para la Investigación y Desarrollo (CAl+D) 2016: Procedimientos de gestión del desarrollo sustentable en áreas inundables con gobernabilidad difusa. El turismo sustentable como estrategia de gestión del desarrollo sustentable en la Micro Región Insular Santa Fe, San José del Rincón y Arroyo Leyes. Director: Mag. Ing. Enrique Mihura.

23) Se trata de un ambiente con paisajes atravesados por riachos, arroyos y zonas de islas que poseen alta biodiversidad, con un patrimonio natural y cultural asociado a esa riqueza, a las huellas de los usos y procesos productivos que en ellos tienen y tuvieron lugar, con poblaciones y dinámicas heterogéneas, servicios e infraestructuras insuficientes, patrones de uso del suelo no concertados interjurisdiccionalmente y dispar grado de concientización y preparación frente a la vulnerabilidad del riesgo hídrico. 
En este proceso, retroalimentado con los ciclos proyectuales de "Guardianes del río" en Alto Verde y La Boca, se viene construyendo la idea de un territorio insular en el que se ha identificado el turismo sustentable como estrategia de desarrollo que entrama cuidado de la naturaleza, patrimonio natural y cultural y generación de oportunidades de empleo e inversión.

Para Pesci (2017), proyectar ambientes es el proceso de regulación de los sistemas complejos. Es la búsqueda de su gobernabilidad. A partir de una concepción relacional, se propone construir sociedades en armonía con la naturaleza, que encaren holística y transdiciplinariamente la realidad, (que reconozcan el valor constitutivo de la matriz natural de todos los territorios), que se valgan de técnicas integradoras, del manejo de todos los tipos de capital, que alienten la planificación de corto, mediano y largo plazo, que integren ciclos retroactivos y unidades productoras en los ecosistemas autorrenovables.

La sustentabilidad es el atributo del modelo de desarrollo deseado (Gallopin, 2004), y la identidad y el patrimonio pueden ser la vía para movilizar este desarrollo por medio de la utilización responsable de la fuerza transformadora del turismo. En este sentido, puede contribuir a concretar algunas de las aspiraciones comunitarias con relación al fortalecimiento de la identidad y al cuidado del patrimonio, en la medida en que se haga de él una actividad económicamente viable, socialmente solidaria, culturalmente enriquecedora y ambientalmente responsable. Para la Organización de las Naciones Unidas, "el turismo ofrece oportunidades significativas como herramienta para el desarrollo sustentable" y es "catalizador de cambios positivos" (UNTWO, 2017) ${ }^{24}$ El turismo sustentable puede generar nuevas oportunidades de empleo, atenuar la pobreza, frenar el éxodo rural de jóvenes y los subempleados así como cultivar un sentimiento de orgullo entre los miembros de las comunidades.

A partir de las experiencias anteriormente narradas, propias y ajenas, y de la oportunidad de dar continuidad a la construcción de los tótems informativos en el paraje, se aborda el diseño de un nuevo mapa. Por las características predominantemente naturales del sitio, y la reducida cantidad de instituciones, la construcción del patrimonio a escala territorial se enfoca desde el concepto de paisaje cultural en su triple función de: oportunidad para el fundamento de la propia identidad, vector para el desarrollo local e instrumento para la reconciliación y la gobernanza (Pesci, 2017).

El paisaje cultural como método busca, a través de su lectura, elaborar la narración (hilo argumental, historia oculta) del territorio (Morón y Estepa, 2015). El análisis procesual del territorio desde la perspectiva del paisaje plantea la descripción y reflexión de los aspectos aparentes (especialmente morfológicos-fenomenológicos) y la interpretación de aquellos otros no aparentes del paisaje. Incluye datos y materiales desde varios ángulos - social y ambiental, pero también ideológico y cultural一, a diferentes escalas geográficas y geológicas ordenadas en una sucesión temporal.

En la búsqueda de nuevos canales de representación, de hilos argumentales para contar la identidad, aparece la idea de incorporar al mapa la serie de postales del patrimonio natural y cultural que se venía diseñando en proyectos anteriores. ${ }^{25} \mathrm{~A}$ este respecto, la imagen es

24) La Organización Mundial del Turismo (OMT) es un organismo internacional creado en 1974 que tiene como propósito promover el turismo. Formalmente vinculada a las Naciones Unidas desde 1976 al transformarse en una agencia ejecutiva del Programa de Naciones Unidas para el Desarrollo.

25) PEIS "Nuevos territorios. Nuevos consensos. Propuesta de desarrollo de turismo sustentable en Paraje La Boca II”. FADU/UNL y PAS: Colección de postales del patrimonio natural y cultural de la Micro Región Insular. 
parte fundamental en la definición de la mirada del territorio y colabora en la conformación de los destinos turísticos como tales. Para las geógrafas Hollmany y Lois (2013), son las imágenes visuales de los lugares las que dan forma y significado a los modos de anticipación a la experiencia turística, son el escenario buscado por el viajero para registrar el acontecimiento y posteriormente para revivir los recuerdos de viaje. Más que una cualidad intrínseca de los objetos y lugares, constituyen una condición social e históricamente construida, responden a aquello que las sociedades que emprenden los viajes turísticos consideran digno de ser visto, visitado.

Estas imágenes pueden, entonces, colaborar en la consolidación de un imaginario para La Boca si se diseñan con una estrategia integradora y responsable: construyendo paisajes y lugares dignos de ser vistos, vividos y visitados.

El mapa resultante y la colección de postales de este sector están en proceso de convalidación por parte de la comunidad barrial a través de talleres participativos y encuestas sobre percepción de valores.

\section{Reflexiones finales: bifurcaciones, aprendizajes y desafíos}

Si decimos que el territorio es el espacio socialmente construido, lo que visibilizamos de él es también una construcción. Todas las acciones humanas dejan una huella en el territorio. En este sentido, las prácticas y proyectos acompañados de la gestión de la SESyC junto con la Red Interinstitucional Alto Verde han sido el vehículo, la oportunidad de interpretar, plasmar e ilustrar la huella cultural que deja una comunidad sobre un sitio profundamente transformado a lo largo de más de un siglo y cada vez más legitimado como espacio urbano de la ciudad de Santa Fe. El principal valor viene siendo la participación activa de la propia comunidad durante los procesos, desde la identificación del problema, el aporte de conocimiento empírico y su mirada como usuarios para la concepción de los distintos dispositivos de representación.

De hecho, el diálogo entre saberes disciplinares y empíricos territoriales estuvo presente en cada etapa de trabajo, en el ejercicio del intercambio transversal y participativo como una impronta, lo que denota que las acciones de extensión en diálogo con el territorio contribuyen a construir huellas visibles del camino recorrido y fortalecer identidad, donde nos transformamos a la vez todos los que participamos.

La Red Interinstitucional y Social Alto Verde ha crecido no solo en la participación de vecinos e instituciones sino en la capacidad para tomar decisiones respecto de políticas públicas del barrio. Este crecimiento es producto de la valorización de actores sociales participantes en la construcción de escenario de confianza colectiva. Por otra parte, las acciones propias de la Red con el gobierno de la provincia o con el municipal, como también las iniciativas de Extensión UNL, fueron el detonante para reconocer su valor no solo como un ámbito de consulta y representatividad sino como espacio desde donde transformar. Así, los conocimientos políticos, científicos, académicos, se complementaron con los aportes de los lugareños para empoderar el proceso de ser y hacer historia barrial. Estas experiencias se hacen posibles en este ámbito superador colectivo que ha encontrado una forma no solo de plantear los problemas sino de convocar y gestionar las soluciones. Así pasó de ser un lugar donde cada uno plantea las dificultades, las problemáticas, a ser un medio de implementación y de articulación de políticas con una fuerte presencia territorial. 
Desde la perspectiva de docentes, pasantes, becarios y estudiantes universitarios, la integración de la extensión al proceso de enseñanza y aprendizaje sin dudas interpela a flexibilizar programas y calendarios, multiplicar horas de dedicación, incorporar días distintos al cursado, de fines de semana, feriados, recesos, a sobrellevar prolongados procesos de negociación, esperar los tiempos comunitarios muchas veces distintos de los universitarios, a debatir, reconocer conflictos, obstáculos propios y barriales, a consensuar y volver a consensuar, admitir autorías múltiples, reconocer oportunidades y aprovechar sinergias. Repensar los territorios que suelen ser vistos como marginados desde el potencial histórico, social, cultural, turístico, y crear lazos cooperativos con organizaciones sociales y actores locales son acciones factibles que encuentran terreno fértil en este tipo de prácticas y proyectos integrados a la agenda académica y a la política pública.

La experiencia de extensión no solo apunta a la democratización de la información recopilada sino que constituye en sí una herramienta fundamental para construir conocimientos compartidos, pensar en el futuro desarrollo junto con el barrio, lo cual resulta propicio para profundizar los procesos de organización popular y autogestión actualmente activos como los potenciales.

$\mathrm{Y}$ algunas otras experiencias vigentes surgen como bifurcaciones, como una novedad derivada del intercambio entre actores académicos con presencia en el territorio. Es el caso del proyecto de investigación orientada sobre movilidad fluvial ${ }^{26}$ en el ámbito de la FADU, que involucra diversas disciplinas y referentes de UNL y otros ámbitos universitarios junto con actores del medio productivo y social. Otro caso es el grupo de las PEEE, también con sede en FADU, sobre la identidad urbana de Alto Verde, ${ }^{27}$ que plantea la continuidad y profundización de la práctica desarrollada en el Momento 2 a partir de una bifurcación hacia el abordaje del espacio privado y su relación con el espacio público ya intervenido, en cuanto a proponer la numeración progresiva de vías circulatorias que permita identificar la residencia de cada habitante, cada hogar, la dirección de cada organización o institución, en el contexto general del barrio; sobre "Aprender a ver el territorio desde la planificación abordando lineamientos urbanos para el Paraje La Boca", ${ }^{28}$ y sobre las infraestructuras de acceso al río, enfocada específicamente en la complejidad del diseño de las infraestructuras de costa en el "Taller de Proyecto Arquitectónico IV. ${ }^{29}$

Desde el área de gestión de la SESyC-UNL fue fundamental la presencia sostenida en las mesas de la Red, donde se han vivenciado escenarios de gran convocatoria, con más de 40 instituciones integrantes, como otras donde pensar estrategias entre seis instituciones y vecinos. Por cuanto todo el tiempo es un reto el acompañar procesos con altibajos,

26) Curso de Acción para la Investigación y el Desarrollo - UNL. Programa de CAI+D Orientado a Problemas Sociales y Productivos - Convocatoria 2016: "Conectando Santa Fe: Movilidad fluvial como oportunidad de integración urbana. El caso de barrio Alto Verde en el marco de la Micro Región Insular (MRI)". Proyecto vigente aprobado por Resolución N632/17 del Consejo Superior de la UNL. Dirección: Ms. Arq. Bruno Reinheimer.

27) PEEE, UNL - Convocatoria 2018: "La identidad urbana de Alto Verde, ciudad de Santa Fe. Ampliación del sistema de referencias espaciales en barrio espontáneo a partir de estrategias de progresividad sobre vías circulatorias". Aprobada por Res. CS de la UNL N¹8/19. Responsable: Ms. Arq. Bruno Reinheimer.

28) PEEE, UNL - Convocatoria 2018: "Aprender a ver el territorio desde la planificación: el caso paraje La Boca". Aprobada por Res. CS de la UNL N¹8/19. Responsable: Arq. Ricardo Giavedoni.

29) PEEE, UNL -Convocatoria 2018: "Arquitecturas para acceder al rio: infraestructuras resilientes en la Alto Verde y La Boca". Aprobada por Res. CS de la UNL N¹8/19. Responsable: Mag. Arq. Patricia Mines. 
atravesados por fenómenos sociales de fragmentación, de descreimiento de la fuerza de la participación social tanto en el territorio como dentro de la Universidad, y así también en momentos de ebullición de problemáticas sentidas cuyas soluciones dependen de definiciones y/o presupuesto de políticas públicas. Es aquí que la Universidad, desde la integración docencia, investigación y extensión, acerca miradas, debates, diseños y capacidades humanas académicas y profesionales posibles. Reconoce los recorridos de los equipos que tienen mayor trayectoria para que animen a otros a proyectar junto con los actores territoriales nuevas propuestas. Insiste también en que los temas consensuados en estos espacios sean fundamentalmente parte de las agendas convocatorias de proyectos de extensión. Puede verse este correlato en cómo ha cambiado la percepción ciudadana de la contribución actual de la UNL en el desarrollo de la ciudad de Santa Fe, donde el 55,6 $\%$ de los entrevistados en la onda de Paneles de Hogares distrito La Costa señala como importante su presencia. ${ }^{30}$

Desde el interior de la Red Interinstitucional y Social Alto verde, el desafío es llegar a concretar la materialización del tótem en La Boca, ya que hay camino avanzado y construido un mapeo colectivo. Al igual que puede ser replicada esta experiencia en otros barrios por su impronta de participación ciudadana, puede ser un modelo de convivencia de los estamentos del Estado, las organizaciones territoriales y los vecinos con un objetivo claro. Fue una experiencia gratificante, de empoderamiento de vecinos, de referentes, donde no solamente cada uno cuidó el progreso de su institución sino ayudó a que puedan verse, creer e identificar sus propios recursos, herramientas de gestión colectivas, a sentirse útiles e importantes en el proceso. También se buscó siempre que fuera un espacio de acción, no de catarsis, y eso fue posible concertando las formas de funcionamiento (tareas, quién lleva las actas, cómo llegar a los acuerdos). Todo empezó desde la informalidad hasta llegar con herramientas propias de trabajo para poder sistematizar todo, con las comisiones, y hasta encontrar soluciones a los problemas que se presentaban en la cotidianeidad del barrio.

El Recursero ayudó a jerarquizar el barrio, esto de tener un asfalto, el nombre de una calle, un letrero, y además un espacio en el que se puedan visualizar las instituciones y el barrio, ahí en una posición de igualdad, donde todos tienen la misma voz y voto para decidir, desde una entidad de algún nivel del Estado hasta alguna organización pequeña de copa de leche. Todo este trabajo de años, minucioso, jerarquizó y potenció al barrio donde hoy podemos, con ayuda del mapa, mostrar la ubicación de los espacios verdes, las instituciones, y al reconocerlos se valorizan y optimizan mucho más.

Al poner en suspenso lo cotidiano, parar, narrar y reflexionar sobre los modos de intervenir desde la extensión universitaria en la UNL, en diálogo con el medio local, ha permitido reconocer el camino recorrido - con vaivenes, obstáculos, facilitadores, desacuerdos y acuerdos, encuentros improvisados y planificados- y renovar el desafío de la gestión universitaria. Y para hacer posibles los cambios y aportar a mejorar la calidad de vida de la población, para que los objetivos se vuelvan realidad, se requiere compromiso, capacidad de reflexión y autoevaluación. En definitiva, "aprendizaje, para dar contenido, claridad, profundidad, relevancia social y proyección política a esta intervención universitaria” (Menéndez et al., 2017). 
Sigue siendo un desafío la mediación entre discursos académicos, políticas universitarias y procesos comunitarios. Al respecto, este artículo colectivo ha sido una oportunidad para identificar trayectos compartidos, repensar y gestar orientaciones a los modelos de intervención territorial.

\section{Referencias bibliográficas}

Albizzati, F.; Dalmolín, A.; Notta, M.; Vastos, R. (2016). Derecho a la Ciudad en contextos vulnerables. Estrategias de integración y revalorización del barrio Alto Verde. Tesis de Grado de la carrera de Arquitectura y Urbanismo (dirección Bruno Reinheimer). FADU-UNL. Santa Fe, Argentina.

Arrillaga, H.; Grand, M. y Busso, G. (2009). Vulnerabilidad, riesgo y desastres. Sus relaciones de causalidad con la exclusión social en el territorio urbano santafesino. En Herzer, H. y Arrillaga, H. (Coords.). La construcción social del riesgo y el desastre en el aglomerado Santa Fe. Santa Fe, Argentina: Ediciones UNL.

Boffelli, M. y Sordo, S. (2016). Fundamentos y perspectivas desde donde pensar la integración de la docencia y la extensión en la Universidad Nacional del Litoral. +E: Revista De Extensión Universitaria, 6(6), 16-23. https://doi.org/10.14409/extension.v1i6.6309

Borja, J.; Muxi, Z. (2003). El Espacio Público: Ciudad y Ciudadanía. Barcelona: Electa.

Dalla Fontana, M. (2019). Distrito Alto Verde. Santa Fe, Argentina: Francisco Sinacori.

Camilloni, A. (2009). Incorporación curricular de la extensión. En UNL, III Congreso Nacional de Extensión Universitaria. Santa Fe, Argentina.

Cortassa, C. (2017). Universidad pública y apropiación social del conocimiento: la renovación del compromiso reformista. +E: Revista de Extensión Universitaria, 7(7), 68-83. https://doi.org/10.14409/extension.v0i7.7052

Dirección de Bibliotecas, Archivos y Museos (DIBAM) (2005). Memoria, cultura y creación. Lineamientos políticos. Recuperado de: https://www.archivonacional.gob.cl/sitio/Contenido/Publicaciones/8380:Revista-Archivo-Nacional-N-5

Fraser, E.; Dougill, A.J.; Mabee, W.E.; Reed, M.; McAlpine, P. (2005). Bottom up and top down: Analysis of participatory processes for sustainability indicator identification as a pathway to community empowerment and sustainable environmental management. Amsterdam: Elsevier.

Frigerio, G. y Diker, G. (2003). Una ética en el trabajo con niños y adolescentes: la habilitación de la oportunidad. Centro de Estudios Multidisciplinarios. Buenos Aires: Novedades Educativas, Fundación CEM.

Guarany, H. (2013). La creciente. Alto Verde querido. 2a. edición. Santa Fe, Argentina: Ediciones UNL.

Gallopin, G. (2004). El Modelo Mundial Latinoamericano ("Modelo Bariloche"): Tres décadas atrás. En Herrera, A.; Scolnick, H.; Chichilnisky, G.; Gallopin, G.; Hardoy, J.; Mosovich, D.; (...) \& Talavera, L. Catástrofe o Nueva Sociedad? Modelo Mundial Latinoamericano 30 años después (pp. 13-26). Buenos Aires: Centro Internacional de Investigaciones para el Desarrollo.

García Canclini, N. (1992). Culturas Hibridas. Como entrar y salir de la modernidad. Buenos Aires: Sudamericana. Harley, J.B. (2005). La nueva naturaleza de los mapas. Ensayos sobre la historia de la cartografía. México: Fondo de Cultura Económica.

Heilbrun, J. (1977). Administración Pública y Política Urbana. Buenos Aires: Marymar.

Herce Vallejo, M.; Magrinyá, F. (2013). El espacio de la movilidad urbana. Buenos Aires: Café de las Ciudades. Hollman, V. y Lois. C. (2013). Geografía y cultura visual. Los usos de las imágenes en las reflexiones sobre el espacio. Rosrio: Ediciones Universidad Nacional de Rosario.

Manzini, E. (2015). Cuando todos diseñan: Una introducción al diseño para la innovación social. Madrid. Experimenta Editorial. 
Menendez, G.; Camilloni, A.; Tarabella, L; Bofelli, M. (2017). Integración docencia y extensión 2. Otra forma de enseñar y aprender. Santa Fe, Argentina: Ediciones UNL.

Menéndez, G. y Tarabella, L. (2016). El aprendizaje experiencial: una práctica de innovación que se afianza en la Universidad Nacional del Litoral. +E: Revista De Extensión Universitaria, 6(6), 96-103. https://doi. org/10.14409/extension.v1i6.6317

Mihura, E. (2013). Gestión responsable del ambiente. Reserva de biósfera en ambiente urbano "Región metropolitana Santa Fe - Paraná". +E: Revista de Extensión Universitaria, 3(3), 66-71. https://doi.org/10.14409/ extension.v1i3.473

Mines, P.; Giavedoni, R. (2016). Guardianes del río. Reflexiones sobre lo que hacemos y aprendemos al lado del agua. +E: Revista de Extensión Universitaria, 6(6), 224-231. https://doi.org/10.14409/extension.v1i6.6346

Morón, M. y Estepa, J. (2015). Las nuevas tecnologías de la información y de la comunicación como recurso para la innovación en la enseñanza de la Geografía. Recuperado de: https://dialnet.unirioja.es/servlet/autor?codigo $=2559634$

Montañez Gómez, G. y Delgado Mahecha, O. (1998). Espacio, territorio y región: conceptos básicos para un proyecto nacional. Cuadernos de Geografía, I/(1-2). Departamento de Geografía, Universidad Nacional de Colombia. Pesci, L. (2017). Del patrimonio urbano al paisaje cultural en áreas urbanas como desafío Nuevos escenarios. Nuevas oportunidades. Aportes para un debate necesario. Hereditas. Tercera época, (27 y 28), 6-19 México: Instituto Nacional de Antropología e Historia.

Pepe, E. (2009). La construcción de la identidad de región. Aportes para una planificación coherente en Comunicaciones Académicas. Actas de diseño IV Encuentro Latinoamericano de Diseño "Diseño en Palermo", IV(7), 246. Buenos Aires. Recuperado de: https://fido.palermo.edu/servicios_dyc/publicacionesdc/vista/detalle_articulo.php?id_libro=16\&id_articulo=5908

Pírez, P (1995). Actores Sociales y Gestión de la Ciudad. Ciudades, (28). México: RNIU.

Rafaghelli, M. (2016). Las Prácticas de Extensión de Educación Experiencial como oportunidad para integrar docencia y extensión. +E: Revista de Extensión Universitaria, 6(6), 8-15. https://doi.org/10.14409/extension. v1i6.6308

Sabatè Bel, J. (2004). Paisajes culturales. El patrimonio como recurso básico para un nuevo modelo de desarrollo. URBAN 9. Revista del Departamento de Urbanismo y Ordenación del Territorio ETSAM UPC. Universidad Politécnica de Cataluña. Recuperado de: http://polired.upm.es/index.php/urban/article/view/380

Shmite, S. y Nin, M. (2007). Geografía cultural Un recorrido teórico a través del diálogo de autores contemporáneos. Huellas, (11), 189.

Valiente, D. (2017-2018). Fichas resumen de cátedra Urbanismo 2 FADU-UNL: Estructura urbana; Trama y tejido; Sistemas de actores y espacio urbano; Paisaje urbano e imagen urbana; Residencia, vivienda, hábitat y sus relaciones con los servicios y equipamientos urbanos. Santa Fe, Argentina.

Zárate Martín, A. (2003). El Espacio Interior de la Ciudad. Madrid: Síntesis.

\section{Documentos institucionales}

Universidad Nacional del Litoral (2005). Informe Final "Monitoreo de las propuestas de acciones de extensión al territorio". Secretaría de Extensión UNL. Grupo de Monitoreo: Cejas, M.; Botta, A.; Heinrich, V.; Raffin, L.; Sosa Sálico, M. Inédito. Uso interno institucional.

- (2010). Proyecto de Desarrollo Institucional. 2010-2019.

(2012). Estatuto Universitario. Resolución AU Nº 04/12. Publicado en el Boletín Oficial Nº 32.609 de fecha 27 de marzo de 2013, ordenado por Resolución N 480/2013 del Ministerio de Educación. 
(2019). Secretaría de Extensión Social y Cultural. Reglamento de Sistema Integrado de Programas y Proyectos de Extensión UNL. Resolución CS N¹6/19.

\section{Páginas Web}

Gobierno de la Provincia de Santa Fe (2019). Plan Abre: https://www.santafe.gov.ar/index.php/web/content/ view/full/193144 (17/06/2019)

International year of Sustentainable Tourismfor development (2017): http://www.tourism4development2017. org/es/

Universidad Nacional del Litoral (2019). Secretaría de Extensión Social y Cultural. Micro Región Insular: https:// www.unl.edu.ar/extension/microregion-insular/ 